\title{
The Relationship Between Social and Cultural Factors with The Willingness of Mothers to Bring Their Babies for Immunization
}

\author{
Siti Zahara Nasution ${ }^{1}$, Abdullah Husein Parinduri ${ }^{2}$ \\ ${ }^{1}$ Faculty of Nursing, University of Sumatera Utara, Indonesia \\ zahara nasutioneyahoo.co.id \\ ${ }^{2}$ Faculty of Nursing, University of Sumatera Utara, Indonesia \\ husein_parindurieyahoo.co.id
}

\begin{abstract}
-immunization is an attempt to confer immunity in infants and children by incorporating the vaccine into the body so that the body makes antibodies body prevent certain diseases. Immunization coverage in 2014 as much $(\mathbf{8 9 . 7 8 \% )}$ ) decreased compared to previous years, this was due to their socio-cultural factors or incorrect understanding on some of the mothers in the area of Medan Denai, as well as a lack of utilization of health services, especially immunization. This study was descriptive correlative aims to determine the relationship between the social and cultural factors with the willingness of mothers to bring their babies for immunization in Medan Denai Community Health Centre. A 100 Family as a respondent were interviewed. Study found that majority of respondents had high school, and the results showed statistically that there is a significant relationship between education and the willingness to bring their children for immunization, respondents did not work (Housewife), showed statistically that there is no significant relationship between education and the willingness to bring their children for immunization, high-income respondents and the result showed statistically that there is no significant relationship between education and the willingness to bring their children for immunization, majority of respondents have Culturally appropriate showed statistically that there is a significant relationship between education and the willingness to bring their children for immunization, majority of respondents have confidence that appropriate and statistically significant relationship between education and the willingness to bring their children for immunization, majority of respondents in a good knowledge statistically significant between education and the willingness to bring their children for immunization.

Expected that the Community Health Centre in Tegal Sari district, Medan Denai to improving health care in their working area, especially in terms of preventive and promotive through education about the importance of immunization by immunization workers and Posyandu cadres.
\end{abstract}

Keywords - Mother, Social Cultural, Immunization, immunity, vaccine

\section{INTRODUCTION}

Indicators to measure the degree of public health which is MMR and IMR. This is because the mother and baby are groups that have a large degree of vulnerability to disease and death. WHO data cited by Save the Children show that each year in the world there are about 1 million infant deaths aged 1 day. In 2013 the infant mortality rate in Indonesia is reported to Save The Children which is 228 per 100,000 deaths, immunization is one indicator that can prevent infant mortality. Health Ministry confirms that the immunization program in Indonesia began in 1956 and in 1990, Indonesia has achieved the status of Universal Child Immunization (UCI), which is a stage where the immunization coverage at an administrative level has reached $80 \%$ or more. Indonesia still has the challenge of realizing a 100\% UCI / District Village in 2014 .

Immunization is an attempt to confer immunity in infants and children by incorporating the vaccine into the body so that the body makes antibodies against the body to prevent certain diseases. While the vaccine is a substance used to induce the formation of antibodies body that is inserted into the body through injection, such as BCG, DPT, measles and polio vaccines. Several years ago, the people of Indonesia has experienced outbreaks of disease that resulted in hundreds of children paralyzed, and some have died. A concrete example is an outbreak of polio in 2005-2006, which caused about 385 children paralyzed, as well as outbreaks of measles in 2009-2011, resulting in about 5818 children were hospitalized, and 16 children died. The latest case happened was diphtheria in East Java in 2011 which led to 1,789 children need to be treated and 91 children died.

The main causes of low achievement of Universal Child Immunization (UCI) are the lack of access to 
services and high dropout rate. This is among other things due to the place of immunization service remote and difficult to reach, the service schedule is irregular and not in accordance with community activities, lack of energy, lack of immunization cards (books KIA), lack of awareness and public knowledge about the benefits, as well as the time of immunization. In addition, socio-cultural factors, education, and socio-economic conditions also affect the low achievement of UCI villages/wards.

Results of a preliminary study conducted by researchers found that the achievement of immunization in the Work Area Health Centre Tegal Sari district of Medan Denai, especially mothers who bring their children for immunization is high enough, in 2012 the number of infants as much as 1,265 people, where toddlers who have been immunized as (90.07\%). In 2013 the number of infants as much as 1,261 people, where a toddler who has been immunized (96.68\%). While in 2014 the number of infants that have been immunized many as 1264 people, of which a toddler who has been immunized $(89.78 \%)$.

Based on the above data it can be seen that from year to year immunization in infants experienced ups and downs, especially in the year 2014 clearly decreased. Although immunization coverage is good enough, but until now there has been no single type of basic immunization reached the target of $100 \%$ as targeted by the North Sumatra Health Office. It is a health problem that needs to be considered, where there are mothers who do not want to bring their babies for immunization due to a lack of willingness mother brought the child immunization and their socio-cultural factors that one thought or understanding on some of the mothers in the area of Medan Denai, as well as lack of utilization of health services, especially immunization

\section{MATERIALS AND METHODS}

\section{A. Type of Research}

The study design used in this research is descriptive correlative which aims to determine the relationship between the independent variables, the relationship socio-cultural factors (Education, Employment, Economy, Customs, Beliefs, Knowledge) with dependent variable is the willingness of mothers to bring their babies for immunization.

\section{B. Analysis Unit / Informant}

Samples were mothers who bring their babies for immunization, with the following criteria: (1) Mothers who have children aged 0-1 years. (2) physical and mental health. (3) Based in the working area of the health center Tegal Sari district. Medan Denai. (4) Available as respondent

\section{Types and Data Collection}

Methods Data analysis is done after the data is collected through several stages. First, check the completeness of identity and data of respondents and ensures that all answers have been filled. In this study, data analysis with statistical methods, demographic data, independent variables and the dependent variable. Analysis of test bivariate will be displayed in tabular form correlation where in this table will be shown how much correlation or relationship between independent variables (education, employment, economy, customs, beliefs, knowledge) with the dependent variable (the willingness mothers bring their babies for immunization), but it also will show whether there is a relationship that occurs or not between the two variables.

\section{RESULTS AND DISCUSSION}

Based on the results of research already shows the characteristics of the demographic data of respondents, which acquired the majority of mothers aged 32 years with the number of 20 people with a percentage of $20.0 \%$. The majority of children aged 4 and 5 respectively 26 people with a percentage of $26.0 \%$. The majority of mothers religion of Islam with the number of 80 people with a percentage of $80.0 \%$. The majority of mothers Batak tribe with the number of 44 people with a percentage of $44.0 \%$. Based on the analysis Chisquare (Pearson Chi-square) showed that there was the significant relationship between education and the willingness to bring the child's immunization ( $p$ $=0.001<0.05$ ). From the results of this study found that the level of education can affect participation and willingness of mothers bring their children to a health center for immunization. This is evident from the 26 mothers were educated College, which has a 
high willingness as many as 22 people $(84.6 \%)$. A person who receives a better education will usually be able to think objectively and rationally. By thinking rationally, then one would be easier to accept the new things that are considered beneficial for themselves and their families. In the opinion of Agrawal and Kumari [1], the level of formal education is the foundation of a person in doing something, create a better understanding and grasp things. The level of formal education also allows differences in knowledge and decision-making. Education provided to the public concerning the willingness to bring children for immunization can use several methods in spreading the message, install confidence in continuous and sustained until they realize, know, understand, willing and able to carry the message. The results are consistent with research conducted by Riadi [2] education has a significant relationship with the willingness to bring children for immunization. However, this study did not concur with those of Tsuchiya [3] which showed the mother's education does not have a meaningful relationship with the complete basic immunization in infants which states that mothers with higher education levels, moderate, and low is not certain that he's done a good action in an effort to bring their children for immunization to health centre, this is due to lack of resources that is known to respondents about immunization so that the respondents did not know the importance of immunization, and still there are states with anxiety/fear. Mothers who have a high school education and universities have a high willingness to bring their children to the immunization clinic, it can be concluded that mothers are aware that immunization is beneficial for children, and immunization is easily available in the health center.

Based on the analysis Chi-square (Pearson Chisquare) shows that there is no significant relationship between the job with a willingness to bring the child's immunization $(p=0.327<0.05)$. The results showed almost no difference in employment of respondents in immunization, this is because mothers who did not have a high willingness to bring their children for immunization is almost no different to working mothers, and respondents who work or not work is still no willingness to set aside time a day to bring their babies to the immunization clinic. This can be proved by comparing the percentage of working mothers with mothers who did not work which would bring their children for immunization, where the mother does not work by $88 \%$, while $84.0 \%$ of working mothers. The results are consistent with research conducted Ali [4] which states that the work of mothers had no effect on the willingness or motivation of mothers to complete their immunization status. This result is in line with Lienda [5] expressed a mother's occupation categories working mother with no work, no employment relationship with the mother's maternal motivation to complete their immunizations. This is because working mothers proportion of children who are immunized almost no different to working mothers. This study is not consistent with research conducted Makamban [6] where there is a significant relationship between the mother's occupation with the basic immunization coverage complete in infants, this happens because the majority of respondents did not work (Housewife) who have more time to immunize their children, and not in a hurry to go home. As for working mothers rarely take their children to health centre due to the schedule of health centre and neighbourhood health centre is open in the morning between the hours of 9 am to 12 noon, where mothers who have jobs will work at that hour so it cannot bring her child immunization in health centre and neighbourhood health centre.

It can be concluded that there are still some things that affect the willingness of mothers bring their children for immunization that mothers should wait their turn, respondents still consider that much of their work to be done than having a long wait for their turn to get their children immunized.

Based on the analysis Chi-square (Pearson Chisquare) shows that there is no significant relationship between economic status with a willingness to bring the child's immunization ( $\mathrm{p}=$ $0.072<0.05$ ).

From the results of research shows that no differences were found between the economic / earnings with the willingness of mothers to bring children for immunization. It is associated with high-income respondents tend to have the same action with the respondent that the low income and 
they both have a high willingness to bring their children to health Centre. No problem with the cost of the immunization, with a family card and KMS book the entire cost of immunization in health centers and neighborhood health center will be free.

According to Notoatmojo [7], the economic / revenue is the amount of real income of all household members who donated to meet the collective needs and individuals in the household, in everyday life earnings are closely related to salaries, wages and other income received someone after the person doing the work in a specified period. The income level of families affected by the work. The lower the family income is increasingly unable to meet all the needs of mothers in the day-to-day and will affect the psychological mother.

The results are consistent with research Simbolon [8], which states that the income variable does not affect the outcome of immunization p-value 0.095. In other words, even though the income of parents is in the category of low, medium or high, but has no effect on the completeness of immunization. Based on the analysis Chi-square (Pearson Chisquare) showed that there was the significant relationship between Customs with a willingness to bring the child's immunization ( $\mathrm{p}=0.000<0.05)$.

The results showed that the majority of mothers are Batak tribe and Java. In Javanese tradition, there is a growing opinion in the community and has been run for generations. One example is the newborn banned out of the house before the 40 days, this can affect the immunization in infants. However, the opinion does not affect the understanding of mothers about immunizations at health centers working area Tegal Sari. This can be evidenced by the data obtained in the field showed that 92 respondents $(92 \%)$ stated that immunization is not contrary to the customs of the mother embrace.

According Sudarma [9], customs created by the ancestors of a tribe or community to dictate our lives and the lives of our descendants. Customs also were also created to produce regularity and order in social interaction. Certain behaviors are run as deemed appropriate by customary law, while a number of other behaviors forbidden because it is considered contrary to the customary rules, considered rude, or causing injury, as well as other types of hazards. Although customs aimed at both and was supposed to provide physical and mental wellbeing to supporters, in fact, there are a number of behaviors based customs provide the potential barriers to health. This study is in line with research Rozalina [10], which indicates that there is a significant relationship between customs/traditions with motivation in immunization hepatitis $\mathrm{B}$. The study also consistent with research Sitepu [11] which showed their customs relations with motivation in awarding immunization.

This study is not in line with the opinion of the Ministry of Health [12] which states that one of the causes of low achievement of immunization due to factors mores that affect the immunization, because there are certain areas in Indonesia that have customs that affect immunization, there are opinions a thriving community that states that every newborn should not be out of the house for immunizations prior to 40 days, and there is also the majority of people who said substances or compounds that exist in immunization vaccine contains a substance that is unclean and not fit for children. But in reality, the Indonesian Ulema Council (MUI) has denied the opinion, MUI has stated that immunization vaccine is halal.

It was concluded that customs mothers profess not contrary to immunization in children. Where customs affect maternal willingness to take their children to the immunization clinic. Customs good mother would facilitate women to understand the importance of immunization activities for children. Based on the analysis Chi-square (Pearson Chisquare) indicates that there is a significant relationship between confidence in the willingness to bring the child's immunization ( $\mathrm{p}=0.001$ $<0.05)$. The research found that most mothers already have confidence that as expected, the mother sure immunizations are useful/helpful for her son. A shared conviction mother will affect the willingness of mothers to bring their children for immunization. The high level of confidence that is owned by the mother to bring the child to the health center immunization cannot be separated from the service received by the mother during a visit to the clinic and completion of existing facilities there are nice, so that mothers tend to choose to bring a child immunization to health center. From another 
opinion some mothers said that officers and cadres of the existing health center already have the skill/ability in immunization in children, it is not out of the education a woman attendant and cadres is high enough, resulting in the delivery of health information to the public to do with precision and clarity.

The confidence is an attitude that is shown by the man when he felt quite knew and concluded that he had reached the truth. Because confidence is an attitude, then one's beliefs are not necessarily true or false, belief alone is not a guarantee of truth. If confidence is not there then doubts will arise, and the error will often stand. The results of this study are not consistent with research Yuzar [13] with the results showing that belief does not have a significant effect on measles immunization. This is because there is the experience of respondents who see the baby becomes ill or a lump at the injection site, redness in place of injections, so the baby is not allowed for the next immunization. This is consistent with the theory that states that the WHO's own experiences or the experiences of others affect a person in a particular behavior. The results are consistent with research Pratley [14] with the results showing that there is a significant relationship between mothers with immunization beliefs. Confidence mothers about immunization that can cause the baby to become a fever, irritability, and swelling on the wane since an explanation of immunization by the officers of health centers as well as the factors of technological advances such as the Internet can be the mother access at any time so that the mother was not too concerned with co-occurring post-immunization. From the results of field research shows that most mothers already have confidence that as expected, the mother sure immunizations are useful/helpful for her son. A shared conviction mother will affect the willingness of mothers to bring their children for immunization. The high level of confidence that is owned by the mother to bring the child to the health center immunization cannot be separated from the service received by the mother during a visit to the health center and the completeness of the facilities that are there good, so that mothers tend to choose to bring the child to the health center immunization. From another opinion some mothers said that officers and cadres in the health center already have the skill/competencies in immunization in children, it is not out of the education a woman attendant and cadres is high enough, resulting in the delivery of health information to society can be done with precision and clarity. From the results of research in the field can be concluded that the majority of the capital own beliefs as expected, where mother assured by immunization in children is the right step to prevent immunization. Based on the analysis Chi-square (Pearson Chi-square) indicates that there is a significant relationship between knowledge with a willingness to bring the child's immunization ( $\mathrm{p}=$ $0.000<0.05$ ).

The results of this study showed that most of the knowledge of the mother in good enough category, where the knowledge of the mother can affect her willingness to bring their baby for immunizations to the health Centre. This is evident from the data obtained, namely 88 respondents who have a good knowledge high willingness as many as 82 people $(93.2 \%)$. Knowledge good mother would facilitate women to understand the importance of immunization activities for children at the health Centre.

Knowledge is also influenced by the experiences related to the age of the individual. Based on demographic data in mind that the average age of the respondents ranged from 25 to 32 . It can be inferred that the more mature person's age will be more life experience you have, and easy to accept changes in behavior because this age is the age of the most productive in particularly instrumental in the formation of health activities. The more a person's age, a level of maturity and strength a person will be more mature in thinking and working. Knowledge is the result of the idea, and this occurred after people perform sensing on a specific object. Sensing occurs through human senses, namely: the sense of sight, hearing, smell, taste, and touch. Knowledge can be obtained from their own thinking and also of other people's thinking. The human ability to recall what is already known, then pass on to others through language causing widespread knowledge.

The results of this study are also consistent with research Ayubi [15] on the contribution of the 
maternal knowledge of the immunization status of children in seven provinces in Indonesia which states there is a relationship between knowledge of mothers with a child's immunization status completeness. And it was found that children who have a mother with a good knowledge have the opportunity to obtain a complete immunization of 2.39 times than in children whose mothers are knowledgeable enough.

According to the assumptions of researchers, the high knowledgeable person more likely to behave well, and is easy to receive information about immunizations, in this case, the mother takes the child is motivated and willing to immunization in health centers. Knowledge is needed as support in foster self-confidence and attitude and behavior every day, so we can say that knowledge is a factor contributing to a person's actions.

\section{CONCLUSION}

Based on research that has been done in the work area public health center Tegal Sari district. Medan Denai can be obtained the following conclusions: (1) The majority of respondents had high school/equivalent, and the results of analysis of Chi-square showed statistically that there is a significant relationship between education and the willingness to bring their children for immunization. (2) The majority of respondents did not work (Housewife), and the results of analysis of Chi-square showed statistically that there is no significant relationship between education and the willingness to bring their children for immunization. (3) The majority of the High-income respondents and the result of analysis of Chi-square showed statistically that there is no significant relationship between education and the willingness to bring their children for immunization. (4) The majority of respondents have culturally appropriate, and the result of analysis of Chi-square showed statistically that there is a significant relationship between education and the willingness to bring their children for immunization. (5) The majority of respondents have confidence that appropriate and Chi-square analysis results show statistically that there is a significant relationship between education and the willingness to bring their children for immunization. (6) The majority of respondents good knowledge, and analytical results Chi-square showed statistically that there is a significant relationship between education and the willingness to bring their children for immunization.

It is expected that the family, especially the mother to be more proactive in seeking information about immunizations by visiting health centers and neighborhood health center so that mothers get the correct explanation of the benefits and immunization schedules.

\section{REFERENCES}

[1] Agrawal, S.C and Kumari, A. (2014). Immunization status of children and the influence of social factors: A hospital based study in western Uttar Pradesh Pediatric Infectious Disease, Volume 6, Issue 1, January-March 2014, Pages 25-30

[2] Riadi, E. (2013). Factors Associated with Motivation Mom Takes Her baby's Immunized In Settlement Trueng Muduro Sawang subdistrict South Aceh District. Terrain: Faculty of Public Health USU

[3] Tsuchiya, et all (2016). Factors associated with mother not vaccinating their children against mumps in Japan Original Research Article Public Health Volume 137, August 2016, Pages 95-105

[4] Ali, M. (2003). Knowledge, Attitudes, and Behavior, and Not Working Mom Working on Completeness of immunization in Tanjung Morawa. Terrain: Thesis Faculty of Medicine USU

[5] Lienda, W. (2009). Factors Associated with Childhood Immunization Completeness 12-23 Djawah Moon in West and Central Java. Jakarta: Thesis Faculty of Medicine UI

[6] Makamban, Y. (2014). Factors Associated with Complete Basic Immunization Coverage in Infants at Work Area Health centers between Makassar. Makassar: Public Health Faculty of Hasanuddin

[7] Notoatmodjo, S. (2012). Health Promotion and Health Behavior. Jakarta: Rineka Reserved

[8] Simbolon, A. (2010). Influence of Social Environment Characteristics and Cultural Capital of the Giving Infant Immunization in Ex. Aek Muara Pinang, South Sibolga. Terrain: Faculty of Public Health USU

[9] Sudarma, M. (2008). Sociology of Health. South Jakarta: Salemba Medika

[10] Rozalina. (2012). Motivation mother in the administration of Hepatitis B immunization in infants at the community health center Sukamara Kab. Sukamara Central Kalimantan Province. Depok: Faculty of Public Health Graduate Program in Public Health UI

[11] Sitepu, S. (2011). Factors Influence Knowledge, Family Support, and Customs / Traditions against Women in Giving Motivation Hepatitis B immunization (0-7 days) in Infants in the village Selotong Secanggang Langkat. Terrain: Faculty of Public Health USU

[12] Minister of Health of the Republic of Indonesia Number: 482 / Menkes / SK / IV / 2010 on the accelerated movement of Universal Child Immunization National Immunization 2010-2014

[13] Yuzar, A. (2010). Factors influence predisposition, Support, and Drivers Mother Baby (Age 9-11 Months) against Measles in Granting Work Area Health centers Sawang Sawang subdistrict South Aceh District. Terrain: Faculty of Public Health USU

[14] Pratley, P.(2016). Associations between quantitative measures of women's empowerment and access to care and health status for mother and their children: A systematic review of evidence from the developing world. Review Article social Science \& Medicine, Volume 169, November 2016, Pages 119-131

[15] Ayubi, D. (2009). Knowledge Capital contribution to Childhood Immunization Status in seven provinces in Indonesia. Depok: Faculty of Public Health UI. 